\title{
Research on Self Compacting Concrete: A Futuristic Concrete
}

\author{
J.Abdul Bari' ${ }^{1}$, S.Umamageshwaran ${ }^{2 *}$ \\ ${ }^{I}$ Associate prof, Department of Civil Engineering, K.S.Rangasamy College of Technology, Tiruchengode-637215, \\ Tamil Nadu, India. \\ ${ }^{2}$ PG Student (ME, Structural Engineering), Department of Civil Engineering, K.S.Rangasamy College of Technology, \\ Tiruchengode-637215, Tamil Nadu, India.
}

*Corresponding author E-Mail ID: umamageshwaran97@gmail.com

Doi: https://doi.org/10.34256/irjmtcon61

\begin{abstract}
Concrete is most widely used in the construction industry and now-a-days Self compaction concrete is used because of its easy flow able properties and reduction in construction time. Self compacting concrete (SSC) is a basic type of concrete that does not required any kind of compaction or vibration. SCC was first developed by Okamura in Japan during the year 1980. This type of concrete flows easily around the reinforcement and into all corners of formwork and also it saves time, labor and energy. Different admixtures are used to produce effective self compacting concrete (SCC). The workability characteristics of SCC will be evaluated by the following tests like Slump Flow, V- Funnel, L-box Test. Many researches were carried out around the world with regards to different applications on properties and mix proportions. This paper includes the literature reviews related to behavior of self compacting concrete also deals with the strength and behavior of self compacting concrete using fibrous materials and mineral admixtures.
\end{abstract}

Keywords: Self Compacting Concrete, Admixtures, Steel fiber, Sisal fiber, highly workable concrete

\section{INTRODUCTION}

Any type of compaction or vibration is not required for self-compacting concrete (SCC). It is highly stable because of its own weight. It is famous for its nature of settle down by itself. Hence it is suitable for faster construction and also it is ecofriendly. Due to the advantages of selfcompacting concrete like reduction shrinkage and cracking and also its improvement in mechanical properties there is a demand for self-compacting concrete. Special treatments and practice are required for the use of self-compacting concrete. Various properties of selfcompacting concrete can be studied by testing the samples in the laboratory.

Slump Flow, L Box and V Funnel are the tests used to determine the fresh properties of selfcompacting concrete (SCC). Hence hardened properties of SCC can be determined by compressive strength, flexural strength and split tensile tests. The behavior of self-compacting concrete is experimented under various combination of admixtures and fiber materials to reduce shrinkage and cracking. hence the flexural behavior of the concrete also gets improved.

\section{REVIEW OF LITERATURES:}

P.mahakavi , R.Chitra (2019) The author experimented on the fresh and hardened properties of self-compacting concrete reinforced with hybrid and crimped fiber in different fiber fractions. In this present investigation the mix proportions of hooked end fiber $(0.25,0.5$ and 0.75 
J.Abdul Bari \& S.Umamageshwaran / International Research Journal of Multidisciplinary Technovation /2019, 1(6), 439-445

$\%)$ and crimped fiber $(0.25$ and $0.5 \%)$. The fresh properties of self-compacting concrete were assessed by slump flow, V Funnel and L Box tests. The hardened properties of self-compacting concrete (SCC) were characterized by using compressive strength, flexural strength and impact resistance tests. The results showed that due to the addition of hooked end and crimped end fiber improves the compressive strength, flexural strength and impact resistance. Hooked end fiber improves compressive strength when comparing to the crimped end fiber, but crimped end fiber reduces the effect of hooked end fiber in flexural strength improvement [1].

Mohammad Ghasemi, Mohammad Reza Ghasemi, Syed Roohollah Mousavi (2019) the author studied that the laboratory results of fracture parameters and brittleness of selfcompacting steel reinforced concrete. With varying water cement ratio, 180 different size notched beams were built and tested under three-point loading. SEM (Size Effect Method) and WFM (Work Fracture Method) are used to investigate and analyses the fracture parameters. Result shows that the size effect may get reduced at some cases. Both SEM and WFM are used to calculate the fracture energy and it was found to be about 9.6 for self-compacting steel fiber reinforced concrete [2].

Mehmet ErenGulsan, RadhwanAlxeebaree, Ayad Ali Rasheed,Anil Nis ,Ahmet EminKurtoglu(2019) This study investigates the effect of nano silica and steel fiber on the fresh and hardened state performance of self-compacting geopolymer concrete (SCGC).For this purpose, self-compacting geopolymer concretes with nano-silica $(0,1 \%$ and $2 \%)$.and with steel fiber ( $0,0.5$ and $1 \%$ ) were produced. An aspect ratio of 40 and length of $30 \mathrm{~mm}$ hooked end steel fibers were used. Binder ratio of 0.5 with constant alkaline activator, $50 \%$ ground granulated blast furnace slag and $50 \%$ of fly ash were used for self-compactinggeopolymer concrete mixes. For alkaline activator, $\mathrm{Na} 2 \mathrm{Sio} 3$ and $\mathrm{NaOH}$ were utilized with a ratio of 2.5. To experiment the effects of nano-silica and steel fiber together on the resulting performance of SCGC specimens the fresh properties tests like Slump Flow, V Funnel and L Box tests were conducted and the hardened properties tests like compressive strength test, flexural strength test and bonding strength were also conducted. The test results demonstrated that incorporation of nano-silica and steel fiber affected the fresh state properties adversely; however, a combined utilization of them improved [3].

M.G. Alberti, A. Enfedaque, J.C. Galvez (2019)The author investigated the flow of SCC enhances the positioning of the fiber and therefore the residual tensile strength of the composite material. Consequently, study of the theology of SCC-FRC permits the characterization and classification of the mix and provides a remarkable tool for design. That is to say, it is essential in analyzing fresh state not only by conventional slump flow tests but also by associating such results with those obtained by remoter. The significance of this research lies in the comparison of the fresh-state results obtained through slump flow and V-funnel tests with those from a BTRemoter, using two types of SCC and both steel and polyolefin fibers. The results show the remarkable influence of the type of fibers and limitations of measurement in terms of physical parameters. This provides relevant information for future applications of the fresh state of FRCSCC whether using steel or polyolefin fibers [4]

Zeynep AlginA, Mustafa Ozen (2018) The author studied clearly about the use of basalt fiber in the production of self-compacting concrete (SCC) to identify the fresh and hardened properties of SCC. The basalt fibers of 3, 6, 12 and $24 \mathrm{~mm}$ in length are incorporated into the SCC mixtures as $0 \%, 0.1 \%, 0.3 \%$ and $0.5 \%$ of concrete volume. After the progression of flow diameter, T500 flow time and V-funnel time tests on the fresh SCC, the tests of compressive strength, flexural strength, splitting tensile strength, rapid chloride permeability and water penetration have been conducted to identify the hardened properties of SCC produced with basalt fiber.The results reveal that the use of basalt fiber decreases the workability but improves the mechanical properties of SCC. The highest flexural and splitting tensile strength results are 
obtained from the concrete mixtures incorporated with the content of $0.5 \%$ fiber having the length of $24 \mathrm{~mm}$. Whereas, the highest compressive strength result is obtained from the mixtures containing the fiber content of $0.1 \%$ for the utilized fiber lengths of $12 \mathrm{~mm}$ and $24 \mathrm{~mm}$. The optimum volume fraction and length of basalt fiber are determined as $0.49 \%$ and $21.12 \mathrm{~mm}$ considering the optimized strength and permeability-based durability properties of SCC [5].

Juliana PetermannMoretti, Sandra Nunes, AlmirSales (2018) The aim of the current study by the author is to assess the feasibility of incorporating sugarcane biogases ash (SBA) from the sugar and ethanol industry as a filler material in the production of self-compacting concrete (SCC). For this purpose, paste composition was designed in the first stage of this study by conducting an experimental plan at the mortar level. During the second stage, SCC mixture properties were evaluated by considering the paste mixture proportions defined in the first stage. Hence the fresh state, mechanical, and durability properties were evaluated. Mortar and concrete test results revealed that SBA can be used successfully in powder-type SCC as a filler material, and it exhibits good self-compacting ability and strength levels, which are adequate for many current civil engineering applications [6].

Mohammed Abed, Rita Nemes(2019) In this journal the author reveals durability tests for twenty-one self-compacting high-performance concrete (SCHPC) mixtures by using recycled concrete aggregate (RCA) and three other unprocessed waste powder materials. They are unprocessed waste fly ash (UWFA), waste perlite powder (WPP) and waste cellular concrete powder (WCCP). The Chloride migration, water penetration, absorption and freeze/thaw resistance have been investigated at different ages up to 270 days and the results showed that using RCA has no significant effect on the durability properties of SCHPC when used up to 50\%. Concretes produced using UWFA or WPP as a replacement of cement mass up to $15 \%$ showed excellent durability performance regardless if the coarse aggregate used was natural aggregate (NA) or RCA. SCHPC proved it can be produced as a green concrete, where the pozzolanic activity and the amorphous waste powder materials help the concrete resist aggressive environments. Using WCCP is not recommended for the purpose of enhancing the durability of SCHPC, as well as excessive replacement amounts of either WPP or UWFA. In general, the effects of both WPP and UWFA on durability properties became more significant due to the hydration proceeding with age [7]

M.G. Alberti, A. Enfedaque, J.C. Galvez (2018) The author experimented that the Fiberreinforced self-compacting concrete uses the flow ability of concrete in fresh state to improve fiber orientation, in due course enhancing toughness and energy absorption capacity. In the past few years there has been a boost in the development of concretes with macro-synthetic fibers added. In this paper the mechanical properties of a self-compacting concrete with low, medium and high-fiber contents of macro polyolefin fibers are studied. Their fracture behavior is compared with a plain self-compacting concrete and also with a steel fiber-reinforced selfcompacting concrete. The results obtained showed that a polyolefin fiber-reinforced selfcompacting concrete has fracture properties analogous to a steel fiber-reinforced self-compacting concrete. Furthermore, it is possible to fit this behavior within the existing standards requirements. Dispersion obtained for fracture mean values among the different amounts was analyzed by using a fracture surface analysis and the amount and distribution of fibers [8]

Sadoon Abdallah, David W.A. Rees, SeyedHamidreza Ghaffar, Mizi Fan(2018)Author conducted, A series of uniaxial tensile tests on cylinders made from steel fiber reinforced selfcompacting concrete (SFR-SCC) have been carried out to investigate the influence of fiber geometry and the combined effect of fiber content and distribution on the post-cracking behavior. Three types of commercially available hooked end fibers 3D (single hooked), 4D (double hooked) and 5D (triple hooked) have been used in this study, which are added to the concrete mixture at two fiber dosages $(0.5$ and $1 \%$ by volume). The experiments show that the post-cracking strength 
increases significantly $(\mathrm{P}<0.05)$ with the increase of fiber content for all mixtures. The combination of a unique shaped hook of high tensile strength demonstrates an optimum effect on the failure mode of concrete cylinders in which peak and post-peak strengths are raised. Notably, strain-hardening behavior is observed only for cylinders reinforced with 5D hooked end fibers. A correlation between number of fibers exposed on fractured surfaces and post-cracking behavior is established [9].

M.G. Alberti, A. Enfedaque, J.C. Galvez (2018)Reinforcing concrete with macrosynthetic structural fibers has become an alternative due to their capacity to comply with standards to substitute steel bars. Compaction and pouring processes influence fiber positioning and orientation and are of key importance for the effectiveness of fiber-reinforcement. Thisresearch compares self-compacting concrete with vibrated conventional concrete reinforced with severaldosages of polyolefin fibers. The differences between them in fresh and hardened state were assessed andwere more noticeable for high-content of fibers. However, fibers were more evenly distributed in thefracture surfaces of self-compacting specimens and wall effects were more evident in the vibrated concrete specimens [10]

M. Mastali a, A. Dalvand (2018)This paper aims to investigate the effects of replacing cement with silica fume in the reinforced self-compacting concrete with recycled steel fiber and study its mechanical properties and impact resistance. To characterize mechanical properties and impact resistance, 144 specimens with different fiber volume fractions of $0.25 \%, 0.5 \%$, and $0.75 \%$ were experimentally tested. Mechanical properties of specimens were characterized with regard of compressive, splitting tensile and flexural strengths. Concerning the obtained large experimental database, an analytical analysis was performed by using regression analysis to investigate the correlate between the impact and mechanical properties of self-compacting concrete reinforced with recycled steel fibers. In addition, the correlation between the mechanical properties of specimens and the content of the replaced cement with silica fume was also examined. The results revealed that the combined effects of silica fume and recycled steel fiber improved the mechanical properties and impact resistance of specimens. Moreover, linear equations were also developed to correlate mechanical properties and impact resistance of specimens with a high coefficient of determination [11].

Ilhami Demir, ÖzelSevim ,EmrahTekin (2018)This study explores the effects of shrinkage-reducing admixtures (SRA) used in self-compacting concrete (SCC). In this study, SCC mixtures with and without (reference) different SRA dosages were produced to define the optimum SRA utilization rate in SCC mixtures. After deciding the SRA dosage to be used in mixtures, properties of reference and SRA-added SCC mixtures were evaluated by focusing mainly on the workability, strength and durability properties after subjected to either direct water submersion or cyclic Na2SO4 solution. Overall, this study concludes that with a proper selection of SRA dosage, SCC mixtures performing well even under very hazardous environments can successfully be produced and be taken advantage of without sacrificing much of workability and/or mechanical properties and risking the occurrence and further development of shrinkage originated cracking [12]

Kannan V (2019) In this study, the effects of ternary system on corrosion behavior of self-compacting concrete containing self-combusted rice husk ash (SCRHA) and metakaolin (MK) were studied. For that different mix proportions were prepared by replacing ordinary Portland cement (OPC) with SCRHA and MK. The OPC was replaced from $0 \%$ to $30 \%$ by SCRHA or MK as a binary system, whereas from $0 \%$ to $40 \%$ by SCRHA and MK as ternary system. In order to assess the properties of blended self-compacting concrete (SCC), various tests were conducted for fresh state properties (Slump flow test, V-funnel test and L-box test), Strength properties (Compressive strength and splitting tensile strength) and durability properties (Rapid chloride penetration test and potential time study for steel corrosion). From the test results, 
$15 \%$ SCRHA, $10 \% \mathrm{MK}$ and $10 \%$ SCRHA $+10 \% \mathrm{MK}$ blended SCC showed good performance against all fresh, strength and durability properties. The test results also indicated that OPC properties can be effectively modified by the ternary system of SCRHA and MK and enhance various SCC properties [13]

Mahmoud Khashaa Mohammed a, Abdulkader Ismail Al-Hadithi b, Marwa H. Mohammed (2019)This study aims to produce and optimize Eco-efficient self-compacting concrete (SCC) mixes using multi-waste substitutions. The main input parameters of mixes were total binder, fine aggregate and water contents whereas slump flow and compressive strength were the two main operational responses of produced concrete. Limestone powder (LP) and waste Polyethylene Terephthalate (PET) were used in concrete as parts of cement and fine aggregate respectively with high range water reducing admixture (SP) as part of water. Response Surface Methodology (RSM) and multi-objectives optimization using Minitab 17 statistical software were employed for this purpose. Twenty SCC mixes were designed and checked experimentally using Central Composite Design (CCD) concept in RSM. Mathematical models were established and evaluated using analysis of variance test(ANOVA) according to the experimental results. This is in order to define the effectiveness degree of design parameters on the properties required and to adjust the derived mathematical models. Multiobjectives optimization process was adopted to determine the optimum values of the input parameters [14].

KaizhiLiu, Zhonghe Shui , Tao Sun , Gang Ling , Xiao sheng Li , Shukai Cheng (2019)In this study, the effects of incorporating expansive agent on the early-age mechanical properties, shrinkage characteristics and durability tests of self-compacting concrete (SCC) with different supplementary cementations materials (SCMs) are investigated. Fly ash (FA), blast furnace slag (BFS) and met kaolin (MK) are added as partial replacement for cement respectively, while three different kinds of expansive agents are introduced in SCC at $15 \mathrm{wt} . \%, 5 \mathrm{wt} \%$ and 1 wt.\% by cement weight. Results show that SCC presents a slightly lower compressive strength and modulus of elasticity compared to those of reference specimens at early ages, while the pozzolanic reactivity of SCMs lead to an increase the mechanical properties in the long-term strength development. The incorporation of combined magnesia expansive agent and liquid expansion agent indicates a significant reduction in the measurement of autogenously shrinkage and drying shrinkage. Additionally, the chloride ion penetration resistance of SCC is enhanced. Moreover, the combination of magnesia and liquid expansion agents refines pore structure and induces compensation for the auto-desiccation which results in high efficiency in the shrinkage reduction. The optimization revealed that the optimum values of the input factors, LP, PET and SP were $20.1 \%, 2.4 \%$ and $1.16 \%$ by weight respectively. These theoretical values were checked experimentally and the achieved responses were quite similar or higher than the best proposed mix. It was deduced that the developed models can be used to ensure a speedy mix design process by achieving maximum tested properties of eco-efficient SCC [15].

\section{CONCLUSION}

Self-Compacting concrete is an advanced type of concrete which does not requires any vibration or compaction. Most of the researchers have carried out their investigational work to analyze the fresh properties by using slump flow, V Funnel and L Box tests and hardened properties by using compressive strength test, flexural strength test and split tensile test. Hence from those tests they came to know by using various admixtures such as hooked end fibers, crimped steel fibers etc., the flexural behavior of self-compacting concrete gets improved and they reduce the shrinkage and cracking effects, but the compressive strength does not get improved except in some cases. Various mix proportions give various results, so the mix proportions of admixtures determine the characteristics of self-compacting concrete. Hence various admixtures can be successfully used in self-compacting concrete (SCC). 


\section{REFERENCES}

1. Gulsan, M. E., Radhwan Alxeebaree, Ayad Ali Rasheed, A., Nis., A., \& Ahmet Emin Kurtoglu. (2019). Development of fly ash/ slag based self compacting geopolymer concrete using nano-silica and steel fiber. Construction and building Materials, 211, 271-283.

2. Ilhami Demir, Ö. S. (2018). The effects of shinkage - reducing admixtures used in self compacting concrete on its strength and durability. Consstruction and building materials, 172, 153-165.

3. Juliana Petermann Moretti, S. N. (2018). Self compacting concrete incorporating sugarcane bagasse ash. Construction and building materials, 172, 635-649.

4. Kaizhi Liu, Z. S. (2019). Effects of combained expansive agents and supplementary cementitious materials on the mechanical properties,shrinkage and chloride penetration of self compacting concrete. Construction and building material, 211, 120-129.

5. M. Mastali a, A. D. (2016). Use of silica fume and recycled steel fibers in self compacting concrete(SCC) . Construction and building materials, 125, 196-209.

6. M.G. Alberti, A. E. (2014). On the mechaanical properties and fracture behavior of polyolefin fiber reinforced self compacting concrete . Construction and building materials, 55, 274-288.

7. M.G. Alberti, A. E. (2019). The effect of fibers in the rheology of self compacting concrete. Construction and building materials, 219, 144-153.

8. M.G. Alberti, A. Enfedaque, J.C. Galvez. (2015). Comparision between polyofin fiber reinforcced vibrated conventional concrete and self compacting concretee. Construction and building materials, 85, 182-194.

9. Mahmoud Khashaa Mohammed a, A. I.-H. (2019). Production and optiminization of ecoefficient self compacting concrete (SCC) with limestone and PET. Construction and building materials, 197, 734-746.

10. Mohammad Ghasemi, Ghasemi Mohammad Reza, \& Mousavi, S. R. (2019). studying the fraxture parameters and size effect of steel fibre reinforced self compacting concrete. Construction and building materials, 201, 447-460.

11. Mohammed Abed, R. N. (2019). Long term durability of self compacting high performance concrete produced with waste materials. Construction and building materials, 212, 350-361.

12. P.mahakavi, \& R.Chitra. (2019). Impact resistance, micro structures and digital image processing on self compacting concrete with hooked end and crimped steel fiber. Construction and building materials, 220, 651-666.

13. Sadoon Abdallah, D. W. (2018). Understanding the effects of hooked- end steel fiber geometry on the uniaxial tensile behavior of self compacting concrete. Construction and building Materials, 178, 484-494.

14. V, K. (2018). Strength and durability performance of self compacting concrete containing self - combusted rice husk ash and metakaolin . Construction and building materials, 160, 169179.

15. Zeynep Algin A, M. O. (2018). The properties of chopped basalt fiber reinforced self compacting concrete. Construction and Building Materials, 196, 678-685.

\section{ACKNOWLEDGEMENT}

We are very thankful to all the researchers who have done excellent work for drawing attention towards possible usage of various admixtures or waste materialism SCC. Their efforts 
J.Abdul Bari \& S.Umamageshwaran / International Research Journal of Multidisciplinary Technovation /2019, 1(6), 439-445 Will really help in future enhancement of properties of self-compacting concrete. 